ISSN: 2146-3042

DOI: 10.25095/mufad.438774

\title{
Tahakkuk Kalitesi ve Kârın Süreğenliği Arasındaki İlişkinin İncelenmesi: BIST 100 Örneği
}

Hüseyin TEMİ*

\section{$\ddot{O Z E T}$}

Firmanın tarafindan yayınlanan kâr bilgisi dönem faaliyetlerinin özet bir sunumu olması bakımından karar sürecinde önemli bir yere sahiptir. Kâr ve bileșenleri olarak tahakkuk ve nakit akışları arasındaki iliş̧kinin anlaşılması da bu noktada önem taşımaktadır. Bu çalışmanın amacı tahakkuk kalitesine göre gruplandırılmış firmaların kâr süreğenliklerinin hesaplanarak tahakkuk kalitesi ve kâr süreğenliği arasındaki ilişskilerin BIST 100 endeksinde işlem göre firmalar açısından incelenmesidir. Elde edilen sonuçlara göre firmaların tahakkuk kaliteleri ile kâr süreğenliği arasında pozitif yönlü bir ilişki tespit edilmiştir. Daha sonra tahakkuk kalitelerine göre gruplandırllan firmalar, kâr süreğenliği modellerinden elde edilen katsayı ve açıklayıcılık değerleri dikkate alınarak incelenmiştir. Bu kapsamda da gruplandırılmış firmaların kâr süreğenliği katsayıları ve model açıklayıcılık gücü ile tahakkuk kalitesi arasında pozitif yönlü bir iliş̧i olduğu belirlenmiştir. Ayrıca çalışma sermayesi değişimi artan firmaların tahakkuk kalitesinin de düştüğ̈̈ gözlemlenmiştir.

Anahtar Kelimeler: Kâr, Tahakkuk Kalitesi, Kâr Süreğenliği

JEL Sinıflandırması: M40, M41.

\begin{abstract}
Investigation of The Association Between Accruals Quality And Earnings Persistence: BIST 100 Case

\section{ABSTRACT}

The profit information published by the firm has an important place in the decision making process with regards to a summary presentation of the period activities. Understanding of the relationship between profit and its components, accruals and cash flows, is also important in this respect. The purpose of this study is to investigate associations between accrual quality and earnings persistence of firms grouped according to the accrual quality within the context of firms that operating in BIST 100 index. According to obtained results there is a positive relationship between accrual quality and earnings persistence. Thereafter firms that grouped by the accrual quality have been investigated by taking into consideration the coefficients and explanatory powers obtained from earnings persistence models. In this context, it is determined that there is a positive relationship between the earnings persistence coefficients and the model explanatory power and the accrual quality of the grouped firms. In addition, it is observed that accrual quality of firms that increase the changes in working capital also decrease.
\end{abstract}

Keywords: Earnings, Accrual Quality, Earnings Persistence

Jel Classification: M40, M41.

\footnotetext{
* Dr. Öğretim Üyesi Hüseyin Temiz, Bozok Üniversitesi, huseyintemiz1@hotmail.com
} 


\section{GíRiş}

Gelişmiş bir muhasebe ve raporlama sistemi firmaların uyguladıkları politikalar ve sürdürdükleri faaliyetlerin cari ve gelecek dönem sonuçlarına olan etkilerini gösteren en temel ve güvenilir bilgi kaynağıdır. Bu kapsamda değerlendirildiğinde muhasebe ve raporlama sisteminin amacı finansal tablo kullanıcılarına firmaları değerlendirmeleri ve karar süreçlerinde kullanmaları için tutarlı ve güvenilir bilgiler sunmaktadır. İhtiyaç duyulan bilgilerin sistematik bir şekilde kaydedilmesi, saklanması ve güvenilir bir şekilde sunulması firma içi ve firma dışı finansal tablo kullanıcılarının karar süreçlerinin daha etkin bir hale getirilmesi bakımından önem taşımaktadır. Tahakkuk esaslı muhasebe sistemi de bu noktada finansal tablo kullanıcılarına yardımcı olmaktadır.

Tahakkuk esaslı muhasebe sistemi firmanın kârı ve bileşenlerinin sunumunda cari dönem nakit akışlarına göre daha iyi bir yöntemdir. Tahakkuk esaslı muhasebede, firmanın nakit akışı dönemde gerçekleşen işlemlerinin yanında, nakit akışı dönemlere yayılmış işlemleri de kaydedilmektedir. Firmanın dönemde gerçekleştirdiği satın alımlar, üretim, satış ve diğer faaliyet sonuçlarına ait nakit akışları cari dönemde gerçekleşmemiş olsa bile tahakkuk temelli muhasebe tarafindan dikkate alınmaktadır (Financial Accounting Standards Board, 1978).

Dönem sonunda yayınlanan kârın temel olarak iki amaca hizmet edeceği düşünülebilir. Bunlardan birincisi, cari dönem faaliyet performansının doğru bir şekilde sunumudur. Diğeri ise gelecek dönem performansının gerçekçi bir şekilde tahmin edilebilir olmasıdır. Bu kapsamda kârın firma finansal sonuçlarını sunması, süreğen ve tahmin edilebilir olması gerekmektedir. Kârın arzu edilen özellikleri taşıması, yapılacak değerlendirmelerde, karar süreçlerinde ve diğer kullanım alanlarında da elde edilecek sonuçların arzu edilen şekilde olmasına katkı sunacaktır. Kârın söz konusu gereklilikleri karşılaması için tahakkukların eşleşme görevini kusursuz bir şekilde yerine getirmesi önem taşımaktadır.

Muhasebe literatüründe konunun incelenmesi iki temel bakış açısı ile özetlenebilir. Bunlardan birincisi Muhasebe Standartları Kurulunun (FASB) değerlendirmesine de uygun olarak tahakkuk esaslı muhasebe uygulamaları kapsamında yapılan raporlamanın firmanın gerçek finansal durumunu yansıtma konusunda nakit esaslı yönteme göre daha iyi olduğunun değerlendirildiği bakış açısıdır. Bir diğer bakış açısı ise, tahakkuk esaslı muhasebe uygulamalarının yöneticiye sağladığı esnekliklerin kullanılarak finansal raporlara müdahale etme eğilimi ile (kâr yönetimi uygulamaları) tahakkukların kullanılmasını konu almaktadır. Bu noktada Dechow ve Dichev (2002) kâr yönetimi uygulamalarının olmadığı bir ortamda da tahakkuk kalitesinin sistematik olarak firma ve endüstri karakteristiklerinden etkileneceğini belirtmiştir. $\mathrm{Bu}$ noktadan hareketle tahakkuk ve kâr kalitesi firma veya endüstri karakteristiklerinden ya da kâr yönetimi uygulamalarından etkilenmesinden ziyade bir fayda maliyet kapsamında ele alınmıştır. Buna göre tahakkuk esaslı muhasebe uygulamalarının faydası nakit akışlarının eşleşme problemini dengelemesi olarak, maliyeti ise yapılan tahmin ve varsayımlardan kaynaklanan hatalar olarak ifade edilmiştir. Söz konusu durumların da bilinçli olsun ya da olmasın tahakkuk ve kâr kalitesi üzerinde etkili olacağ değerlendirilmiştir.

$\mathrm{Bu}$ çalışmanın amacı tahakkuk kalitesi (çalışma sermayesi değişimi, kısa vadeli tahakkuklar) ve kâr süreğenliği arasındaki ilişkinin Türkiye örnekleminde incelenmesidir. 
Çalışmanın temel motivasyonu, yapılan literatür incelemesi kapsamında daha önce incelenmediği değerlendirilen bir örneklem grubu ve zaman diliminde incelemenin yapılmasıdır. Tahakkuk kalitesi ile kâr süreğenliği arasındaki ilişkilerin incelenmesi amacıyla literatürde mevcut tahakkuk kalitesi ve kâr süreğenliği modellerinden yararlanılmıştır. Elde edilen bulgular kapsamında tahakkuk kalitesi ve kâr süreğenliği arasında pozitif ve anlamlı ilişkiler olduğu tespit edilmiştir. Ayrıca çalışma sermayesi değişimi artan firmaların tahakkuk kalitesi göstergelerinde de düşüş meydana geldiği görülmüştür.

Çalışma kapsamında birinci bölümde tahakkuk kalitesi ve kâr süreğenliği konuları ele alınmıştır. İkinci bölümde tahakkuk kalitesi ve kâr süreğenliği hakkında bilgiler sunulmuştur. Üçüncü bölümde literatürde yer alan çalışmalara yer verilmiştir. Dördüncü bölümde ise çalışmada kullanılan veri, yöntem ve bulgular sunulmuştur. Çalışmanın son bölümünde ise sonuç ve öneriler raporlanmıştır.

\section{TAHAKKUK KALITTESİ VE KÂRIN SÜREĞENLİĞİ}

Tahakkuk kelimesi Türk Dil Kurumu'na göre gerçekleşme, yerine gelme anlamı taşımaktadır. Muhasebe terimi olarak da gerçekleşmiş bir olayı ifade etmektedir. Örneğin dönem içinde yapılan bir kredili satış aynı dönemde tahsil edilmemiş dahi olsa firmanın yayınladığ 1 kâr/zarar tablosunda raporlanmaktadır. Söz konusu işlem tahakkuk teriminin muhasebe alanındaki kullanımını yansıtmaktadır. İfade edilen kredili satışın dönem faaliyeti olması nedeniyle finansal tablolarda yayınlanması, firmanın dönem performansı hakkında sunulacak bilgilerin doğruluğu açısından faydalı bir yaklaşımdır. Ancak söz konusu satışın iade edilmesi veya alacağın tahsilinde meydana gelecek herhangi bir beklenmedik durum söz konusu tahakkuk işleminin kalitesini düşürecektir. Bu olumsuz durum kuşkusuz kredili satış1 içeren dönem kârının kalitesi üzerinde de etkili olacaktır.

Firmanın cari dönemde gerçekleşen çalışma sermayesi değişimi ya geçmiş yıl işlemlerinden cari döneme sarkan nakit akışlarından $\left(\mathrm{CFO}_{t-1}\right)$, ya cari dönemde gerçekleşen olaylardan $\left(\mathrm{CFO}_{t}\right)$ ya da cari dönemde tahsil edilen fakat gelecek dönemde $\left(\mathrm{CFO}_{t+1}\right)$ gerçekleşen işlemlerinden oluşmaktadır. Bu noktadan hareketle cari dönem faaliyetten sağlanan nakit akışlarının bir önceki ve bir sonraki yıla ait nakit akışları toplamından oluştuğu ifade edilebilir (Dechow \& Dichev, 2002).

Nakit akışları objektif bir yapıya sahiptir ve denetçi tarafindan kolayca doğrulanabilir. Ancak bazı tahakkuk hesapları belirlenirken profesyonel muhakeme gerekir. Amortisman, alacaklar ve koşullu yükümlülükler bu duruma örnek olabilir. Muhakemenin söz konusu olduğu durumlarda tahakkuk ve nakit akışlarının eşleşmesinde zaman zaman farklar oluşmaktadır. Söz konusu durum tahakkuk işleminin barındırdığı hatadan kaynaklanmaktadır. $\mathrm{Bu}$ hatalar bilinçli veya bilinçsiz olarak meydana gelmiş olabilir. Bilinçli hatalar yöneticinin fursatçı bir şekilde muhasebe esnekliklerini kullanması sonucu oluşabilir. Diğer taraftan eşleşme problemi bilinçsiz bir yapıda da gerçekleşebilir. Ancak her iki durumda da eşleşme probleminin tahakkuk kalitesini düşüreceği bir gerçektir.

Board (1980)'da finansal raporlamanın temel kalitesinin güvenilirlik olduğu ifade edilmiştir. Bunun anlamı, finansal tablo kullanıcılarının firmanın dönem faaliyet sunumları ve altında yatan gerçekleri herhangi bir hata ya da sapma olmadan gerçeğe uygun bir şekilde sunulduğundan emin olmalarıdır. $\mathrm{Bu}$ kapsamda değerlendirildiğinde muhakemeden 
kaynaklanan hataların artmasının tahakkuk kalitesi ve güvenilirliği etkileyeceği değerlendirilmektedir.

Sloan (1996) çalışmasında kârın tahakkuk bileşeninin nakit akışı bileşenine göre daha düşük süreğenliğe sahip olduğunu belirtilmiş ve bu duruma büyük ölçüde tahakkukların sübjektif yapısı neden olarak gösterilmiştir. Bu noktada firmanın beklenmedik şekilde yüksek ya da düşük tahakkuklarının düşük kâr süreğenliğgine neden olacağı değerlendirilmiştir. Ayrıca yatırımcıların miyop oldukları, nakit ve tahakkuk bileşenlerinden ziyade kâr tutarına odaklandıkları değerlendirilmiştir. Bu durumun da tahakkuk anomalilerine neden olduğu ifade edilmiştir.

Kârın temel görevi firmanın dönemsel finansal performansını ölçmektir (Financial Accounting Standard Board, 1978). Kâr süreğenliği ise, cari dönem kârına olan etkilerin gelecek dönemlerde de tekrarlanma eğilimi olarak ifade edilebilir (Francis \& Smith, 2005). Tahakkuk işlemlerinin olmadığı ve finansal bilgilerin gerçeği yansıttığı varsayımı altında, firmanın gerçek finansal performansını yansıtan kâr tutarı ile nakit akışının eşleşmesi gerekir. Tahakkuk işlemlerinin olmadığı varsayımı kaldırıldığında, yani nakit giriş/çıkışlarının farklı dönemlerde oluştuğu gerçekçi bir senaryoda, firmanın gerçek finansal performansını yansıtan kâr tutarı ile nakit akışı eşleşmeyecek ve tahakkuklar firma finansal performansının ölçümünde yalnız nakit akışlarına göre daha kapsamlı bir sunumu sağlama görevini üstlenecektir. Ancak tahakkuk esasına göre hesaplanmış kâr tutarı, cari dönem faaliyetlerinin gelecek döneme ilişkin ekonomik faydaları konusunda tahmine dayanması ve hata barındırmasından dolayı tam olarak firmanın gerçek finansal performansını yansıtan kâr ile eşleşmeyecektir (Richardson vd., 2005).

\section{LITERATÜR İNCELEMESI}

Tahakkuk kalitesi ve kâr süreğenliği literatürde pek çok firma karakteristiği kapsamında ele alınmış bir inceleme konusudur. Raporlanan kârın finansal tablolarda yayınlanan bilgiler içinde ayrı bir yere sahip olması tahakkuk, nakit akışı ve kâr arasındaki ilişkiyi inceleyen çalışmaların sayıca fazla oluşunun temel nedeni olarak düşünülebilir. $\mathrm{Bu}$ çalışma ile temel olarak tahakkuk (çalışma sermayesi değişimi) kalitesi ve kâr süreğenliği arasındaki ilişkiler incelenmiştir.

Yapılan çalışmalarda muhasebe kalitesini düşüren tahmin hataları ve tahminin doğruluğunun işlemlerin karmaşıklığ 1 , firma çevresinin tahmin edilebilirliğ i, satışların, nakit akışının ve tahakkukların oynaklığ 1 gibi firma karakteristikleri ile ilişkili olduğu belirtilmiştir. (Dechow \& Dichev, 2002; Palepu vd., 2000; Scholer, 2004).

Richardson vd. (2002) çalışmasında tahakkukların bilgi kaynağı, gelecek dönem kârı ve hisse senedi getirisi arasındaki ilişkiler incelenmiştir. Elde edilen sonuçlara göre düşük tahakkuk güvenilirliğine sahip firmaların daha düşük kâr süreğenliğine sahip olduğu, yatırımcıların bu durumu tam olarak tahmin edemedikleri ve bu nedenle piyasada yanlış fiyatlama eğiliminde oldukları ifade edilmiştir.

Francis vd. (2005) çalışmasında yatırımcıların tahakkuk kalitesini kârla ilgili bir bilgi riski olarak fiyatlandırıp fiyatlandırmadıkları incelenmiştir. Elde edilen sonuçlar düşük tahakkuk kalitesinin yüksek borç ve özkaynak maliyeti ile ilişkili olduğunu göstermektedir. 
Çalışmada ayrıca tahakkuklar ekonomik temellere dayanan (innate) ve yönetim esnekliği kullanılan (discretionary) olmak üzere iki gruba ayrılarak da incelenmiştir. Her iki grup tahakkukların da sermaye maliyeti üzerinde etkili olduğu ancak ekonomik temellere dayanan tahakkukların yönetim esnekliğine dayanan tahakkuklardan daha fazla etkiye sahip olduğu belirtilmiştir. Benzer bir çalışma Gray vd. (2009) tarafindan yapılmıştır. Bu çalışmada tahakkuk kalitesi, bilgi riski ve sermaye maliyeti arasındaki ilişkiler incelenmiştir. İncelenen firmaların borç ve özkaynak maliyetlerinin tahakkuk kalitesinden etkilendiği ve tahakkuk kalitesinin hisse senedi piyasasında da fiyatlanan bir faktör olduğu sonucuna ulaşılmıştır.

Dechow ve Ge (2006) çalışmasında kâr süreğenliğinin tahakkukların hem büyüklüğünden hem de yönünden etkilendiği ifade edilmiştir. Tahakkukların, nakit akışlarına göre yüksek tahakkuk düzeyine sahip firmaların kâr süreğenliğini artırırken düşük tahakkuk düzeyine sahip firmalarda kâr süreğenliğini düşürdüğü değerlendirilmiştir. Bu kapsamda düşük kâr süreğenliği ve düşük tahakkuk düzeyine sahip firmalardaki duruma özel durumların (durdurulan faaliyetler, olağandışı giderler gibi) neden olduğu belirtilmiştir. Ayrıca çalışma kapsamında bu gibi özel durumlara sahip düşük tahakkuk seviyeli firmaların diğer düşük tahakkuk seviyeli firmalara göre daha yüksek gelecek dönem hisse senedi getirisine sahip oldukları sonucuna ulaşılmıştır.

Srinidhi ve Gul (2007) tarafından yapılan çalışmada denetim ücretleri ve tahakkuk kalitesi arasındaki ilişki incelenmiştir. Çalışma kapsamında yüksek denetim ücretlerinin daha yüksek denetim çabalarına neden olacağı ve bunun sonucu olarak tahakkuk yapısı üzerinde daha güçlü muhakeme uygulanacağı varsayımı test edilmiştir. Elde edilen sonuçlar tahakkuk kalitesi ve denetim ücreti arasında pozitif ilişki olduğunu göstermiş ve test edilen hipotezi desteklemiştir. Denetim konusunda yapılan bir başka çalışma da Ittonen vd. (2013)'ne aittir. $\mathrm{Bu}$ çalışmada kadın denetçinin kâr yönetimi ve tahakkuk kalitesi üzerindeki etkileri incelenmiştir. Elde edilen sonuçlar kadın denetçi ile çalışan firmaların daha düşük düzeyde yönetim esnekliği barındıran tahakkuklara sahip olduğunu ve kadın denetçinin kâr yönetimi uygulamalarında kısıtlayıcı rol oynadığını göstermektedir.

Li (2008) çalışmasında firmaların dönem sonu finansal raporlarının okunabilirliğgi, firma performansı ve kâr süreğenliği arasındaki ilişki incelenmiştir. Finansal tablo okunabilirliği Fog Endeksi ${ }^{1}$ kullanılarak hesaplanmıştır. Elde edilen sonuçlara göre düşük kâr düzeyine sahip firmaların finansal tablolarının daha zor okunabildiğini ve okunabilirlik düzeyi daha kolay olan firmaların kâr süreğenliği katsayılarının daha yüksek olduğu belirtilmiştir.

Durak (2010) çalışmasında Uluslararası Finansal Raporlama Standartları (UFRS) uygulamalarının tahakkuk kalitesi ve kâr süreğenliği üzerindeki etkileri incelenmiştir. Çalışmada 1998-2003 yılları tarihi maliyet verilerine dayanan finansal raporlar UFRS öncesi dönem ve 2003-2008 arasında yayınlanan ve UFRS uygulamalarını kullanan finansal raporlar ise UFRS sonrası dönem olarak değerlendirilmiştir. Elde edilen sonuçlara göre UFRS uygulamalarının tahakkuk kalitesini arttırdığı tespit edilmiştir. Ancak kâr süreğenliğinin her iki dönemde de benzer değerlere sahip olduğu gözlemlenmiştir. Çalışmada ayrıca tahakkuklar

\footnotetext{
${ }^{1}$ Fog Endeksi bir metnin kolay okunabilirlik düzeyini göstermektedir. Fog Skoru $=(0.4 *($ ASL + PHW $))$ formülüyle hesaplanmaktadır. Formülde yer alan ASL ortalama cümle uzunluğunu (toplam kelime sayısının toplam cümle sayısına bölümü), PHW ise okunması zor kelimelerin yüzdesini ifade etmektedir (okunması zor kelimeler üç ya da daha fazla hece sayısına sahip olmayı ifade etmektedir).
} 
gruplara ayrılarak kâr süreğenliği ile arasındaki doğrusal ilişki test edilmiş ancak beklenen ilişkiyi destekleyen sonuçlar elde edilmemiştir.

Chen vd. (2013) muhafazakar muhasebe uygulamalarının kâr süreğenliği ve kârın hisse senedi piyasasındaki fiyatlandırma mekanizması üzerindeki etkilerini incelemiştir. Çalışmadan elde edilen sonuçlara göre, daha muhafazakar muhasebe uygulamalarını benimseyen firmaların kâr süreğenliğinin diğer firmalara göre daha düşük olduğu ve daha muhafazakar firmalara ait kâr verisinin hisse senedi piyasası fiyatlama mekanizmasında diğer firmalara göre daha küçük bir yere sahip olduğu belirtilmiştir.

Ozkan ve Kayımlı (2015) tarafindan yapılan çalışmada Türkiye'de faaliyet gösteren firmaların kâr süreğenliği ve bu süreğenliğin nakit akışları ya da tahakkuk bileşenlerinin hangisinden daha çok etkilendiği incelenmiştir. Elde edilen sonuçlara göre BIST’te raporlanan kâr tutarlarının süreğen olduğu ifade edilmiştir. Ancak Türkiye örnekleminden elde edilen süreğenlik katsayısı sonuçlarının gelişmiş ülke firmalarına ait katsayılardan düşük olduğu ifade edilmiştir. Çalışmada ayrıca anormal tahakkuklar nedeniyle toplam tahakkukların nakit akışlarına göre daha düşük süreğenlik gösterdiği değerlendirilmiştir.

Leal vd. (2017) çalışmasında yüksek kâr ve nakit akışı tutarının süreğenlik, değer ilişkisi ve tahakkuk kalitesi üzerindeki etkisi incelenmiştir. Elde edilen sonuçlara göre nakit akışlarının kâra göre daha süreğen olduğu ve bu duruma kârın tahakkuk bileşeninin neden olduğu belirtilmiştir. Kârın tahakkuk bileşeninin süreğenlik katsayının düşük olması dolasıyla nakit akış süreğenliğinin kâr süreğenliğinden yüksek olduğu ifade edilmiştir. Kâr ve nakit akışları ekstrem değerlere sahip firmalarda söz konusu değerlerin kâr ve nakit akış süreğenliği üzerinde etkili olduğu ve bu etkinin nakit akış süreğenliği üzerinde güçlü ve negatif yönlü olduğu tespit edilmiştir. Çalışmada ayrıca yüksek tahakkuk seviyesine sahip firmaların tahakkuk kalitesinin de düşük olduğu değerlendirilmiştir.

\section{VERİ YÖNTEM VE BULGULAR}

\section{1. Çalışmada Kullanılan Veri ve Örneklem}

$\mathrm{Bu}$ çalışmada tahakkuk kalitesi ve kârın süreğenliği arasındaki ilişki incelenmiştir. Bu amaç doğrultusunda BIST 100 endeksinde faaliyet gösteren 100 firmadan analize uygun olan 79 firmaya ait 2005-2015 yıllarını kapsayan veriler kullanılmıştır. Çalışma inceleme döneminin 2005 yılından itibaren başlamış olmasının nedeni, Türkiye'de UFRS uygulamalarının 1 Ocak 2005 tarihinden sonra başlayan dönemler için uygulanmaya başlamış olmasından dolayı firmalara ait verilerin karşılaştırılabilir olmalarının sağlanmasıdır. İnceleme kapsamına alınan firmaların çalışmada uygulanan yönteme uygun olması için inceleme dönemi süresinde endekste kesintisiz olarak yer almalarına dikkat edilmiştir. İnceleme döneminde endeksten ayrilan, eksik veriye sahip olan ve finansal firmalar örneklem dışında bırakıldığında 79 firmaya ait 706 firma-yıl gözlem inceleme kapsamına alınmıştır. Çalışmada kullanılan veriler Datastream veri tabanından temin edilmiştir.

\subsection{Yöntem}

Çalışma iki kısımdan oluşmaktadır. Birinci kısım firmalara ait bireysel tahakkuk kalitelerinin ölçülmesinden oluşmaktadır. İkinci kısımda aynı firmalara ait kâr süreğenliği 
katsayıları hesaplanmaktadır. Bu noktada her bir firma için zaman serisi analiz yöntemi uygulanmıştır. Söz konusu yöntem örnekleme dahil edilen firmaların bireysel olarak en az sekiz yıllık verilerinin yer aldığı bir zaman serisine dayanmaktadır. Zaman serisi, farklı dönemlerde aynı birime ait gözlemlerden oluşan bir seti ifade etmektedir (Gujarati, 2009). Çalışmada kullanılan modeller literatürde benzer çalışmalarda da kullanılmaktadır (P. M. Dechow \& Dichev, 2002).

Tahakkuk kalitesinin ölçümünde kullanılan model aşağıdaki şekilde ifade edilebilir;

$$
\Delta W C=\beta_{0}+\beta_{1} C F O_{t-1}+\beta_{2} C F O_{t}+\beta_{3} C F O_{t+1}+\varepsilon_{t}
$$

Modelde yer alan değişkenler toplam varlıklarla deflate edilmiştir ve aşağıdaki şekilde tanımlanmaktadır.

$$
\begin{aligned}
& \Delta \mathrm{WC}=\mathrm{t} \text { dönemindeki çalışma sermayesi değişimi } \\
& \mathrm{CFO}=\text { döneme }(\mathrm{t}-1, \mathrm{t}, \mathrm{t}+1) \text { ait faaliyetten sağlanan nakit akışları }
\end{aligned}
$$

Modelde çalışma sermayesindeki değişimin kısa vadeli olması, yani bir yıl içinde gerçekleşen olaylardan kaynaklandığı ve bu yüzden değişimin de faaliyetten sağlanan nakit akışlarının geçmiş, cari ve gelecek dönem nakit akışlarında gerçekleşeceği varsayımı yer almaktadır. Modelin kalıntı değeri nakit akışına dönüşmeyen çalışma sermayesi değişimlerini ifade etmektedir. Söz konusu kalıntı değerlerin standart sapması da firma düzeyinde tahakkuk kalitesi göstergesi olarak değerlendirilmektedir. Yüksek standart sapma değeri düşük tahakkuk kalitesini, düşük standart sapma değeri ise yüksek tahakkuk kalitesini ifade etmektedir (Dechow \& Dichev, 2002).

Söz konusu model her firma için ayrı ayrı kurulmuş ve firmaya ait kalıntı değerler hesaplanmıştır. Elde edilen kalıntı değerlerin standart sapmaları hesaplanarak firmaların tahakkuk kalitesine ait nihai gösterge değerlerine ulaşılmıştır.

Çalışmada tahakkuk kalitesi ile arasındaki ilişkinin incelenmesi amacıyla firmalara ait kârın süreğenliği göstergesi aşağıdaki model yardımıyla hesaplanmıştır;

$$
{\text { Earning } s_{t+1}}=\beta_{0}+\beta_{1} \text { Earnings }_{t}+\varepsilon_{t}
$$

Modelde yer Earnings değişkeni firmanın t dönemindeki kârının toplam varlıklara bölünmüş halini ifade etmektedir. Modelde dönem kârının bir sonraki dönem kârını açıklama gücü ve dönem kârının katsayı değeri ile çıkarımlar yapılmaktadır. Kâr süreğenliğinin bir kalite göstergesi olarak kullanımının altında yatan mantık, iki firmadan daha yüksek süreğenlik katsayısına sahip olan firma dönem kârının gelecek dönem performansı hakkında daha kullanışı bir özet bilgi olması ve değerleme modellerinde yüksek süreğenlik katsayısına sahip firma kârının daha düşük değerleme hatasına sahip olacağıdır (Dechow vd., 2010).

\subsection{Bulgular}

$\mathrm{Bu}$ başlık altında çalışmada kullanılan modellerde yer alan değişkenlere ait tanımlayıcı istatistikler, korelasyon analizine ait bulgular ve analiz bulguları değerlendirilecektir. 


\subsubsection{Tanımlayıcı İstatistikler ve Korelasyon Bulguları}

Çalışmada kullanılan değişkenlere ait tanımlayıcı istatistikler Tablo 1'de sunulmuştur.

Tablo 1. Tanımlayıcı İstatistikler

\begin{tabular}{lcccccc}
\hline & ACCRUAL & $\Delta$ WC & EARNINGS & CFO $_{t-1}$ & $\mathrm{CFO}_{t}$ & $\mathrm{CFO}_{t+1}$ \\
\hline Ortalama & $-0,02$ & 0,05 & 0,06 & 0,09 & 0,08 & 0,08 \\
Ortanca & $-0,02$ & 0,03 & 0,06 & 0,08 & 0,08 & 0,08 \\
En Yüksek & 1,06 & 0,99 & 0,58 & 2,26 & 0,73 & 0,73 \\
En Düşük & $-0,60$ & $-0,54$ & $-0,42$ & $-1,05$ & $-1,05$ & $-1,05$ \\
Std. Sapma & 0,13 & 0,11 & 0,09 & 0,18 & 0,14 & 0,14 \\
Gözlem Saylsi $^{2}$ & 706 & 706 & 706 & 706 & 706 & 706 \\
\hline Accul $^{2}$ & & & & & &
\end{tabular}

Accrual $=$ Earnings - CFO olarak hesaplanmıştır.

$\Delta \mathrm{WC}=(\Delta$ Alacaklar $+\Delta$ Stoklar $-\Delta$ Borçlar $-\Delta$ Ödenecek vergi $+\Delta$ Diğer varlıklar $)$ olarak hesaplanmıştır.

Earnings $=$ Firmaların gelir tablosunda yer alan dönem kârını ifade etmektedir.

$\mathrm{CFO}=$ Firma nakit akış tablosunda yer alan faaliyetten sağlanan nakit akışını ifade etmektedir.

Tüm değişkenler otalama toplam varlıklarla deflate edilmiştir.

Tablo 1'de yer alan bulgular incelendiğinde, inceleme döneminde kârın $(0,06)$ nakit akışının $(0,08)$ gerisinde olduğu görülmektedir. Bu durumun doğal bir sonucu olarak tahakkuklar inceleme döneminde -0,02 değerine sahiptir ve bu duruma imalat sektöründe yer alan firmaların maddi duran varlık yoğun olmalarından kaynaklanan amortisman giderinin neden olduğu düşünülebilir. Çalışma sermayesindeki değişimin pozitif değere $(0,05)$ sahip olması da firmaların büyüme eğiliminde oldukları şeklinde yorumlanabilir. Değişkenler arasındaki korelasyon bulguları Tablo 2'de raporlanmıştır.

Tablo 2. Korelasyon Bulgular1

\begin{tabular}{lllllll}
\hline & ACCRUAL & $\Delta \mathrm{WC}$ & EARNINGS & $\mathrm{CFO}_{\mathrm{t}-1}$ & $\mathrm{CFO}_{\mathrm{t}}$ & $\mathrm{CFO}_{\mathrm{t}+1}$ \\
\hline ACCRUAL & 1 & & & & & \\
$\Delta \mathrm{WC}$ & $0,75^{* * *}$ & 1,00 & & & & \\
EARNINGS & $0,21^{* * *}$ & $0,21^{* * *}$ & 1,00 & & & \\
$\mathrm{CFO}_{\mathrm{t}-1}$ & $-0,11^{* * *}$ & $0,21^{* * *}$ & $0,33^{* * *}$ & 1,00 & & \\
$\mathrm{CFO}_{\mathrm{t}}$ & $-0,80^{* * *}$ & $-0,57^{* * *}$ & $0,42^{* * *}$ & $0,31^{* * *}$ & 1,00 & \\
$\mathrm{CFO}_{\mathrm{t}+1}$ & $-0,21^{* * *}$ & 0,04 & $0,31^{* * *}$ & $0,28^{* * *}$ & $0,39 * * *$ & 1,00 \\
\hline
\end{tabular}

$* \% 10, * * \% 5$ ve $* * * \% 1$ düzeyinde anlamlı sonuçları ifade etmektedir.

Tablo 2'de raporlanan bulgular değerlendirildiğinde toplam tahakkukların nakit akışlarının bir önceki, cari ve bir sonraki dönemleriyle arasında negatif korelasyon katsayısına sahip olduğu görülmektedir. Çalışma sermayesi değişimi ile toplam tahakkuklar arasında da pozitif yönlü hayli yüksek korelasyon katsayısı $(0,75)$ tespit edilmiştir. Buradan yola çıkarak çalışma sermayesinin büyük ölçüde toplam tahakkuklardaki değişimi içerdiği ifade edilebilir.

\footnotetext{
${ }^{2}$ Çalışmada kullanılan modellerde değişkenlere ait önce ve sonraki dönemlere ihtiyaç duyulduğu için 864 firmyıl veri seti 706 firma-yıla düşmektedir.
} 
Dönem kârının ise nakit akışlarının bir önceki, cari ve bir sonraki dönem değerleriyle pozitif korelasyon katsayılarına sahip olduğu görülmektedir.

Tablo 2'de çalışma sermayesindeki değişim ile nakit akışların bir sonraki dönemi arasında 0,04 düzeyinde ve anlamsız korelasyon katsayısı olduğu görülmektedir. Aslında dönem çalışma sermayesi değişimi ve gelecek dönem nakit akışları arasında pozitif ve istatistiksel olarak anlamlı korelasyon katsayısı beklenmektedir. Bu durumun nedeni $\Delta \mathrm{WC}$ ile $\mathrm{CFO}_{t}$ arasındaki negatif korelasyon katsayısı $(-0,57)$ ve $\mathrm{CFO}_{t}$ ve $\mathrm{CFO}_{t+1}$ arasındaki pozitif korelasyonun $\Delta \mathrm{WC}$ ve $\mathrm{CFO}_{t+1}$ arasındaki ilişkinin etkisini gidermesi olabilir. Söz konusu durum kısmi korelasyon (partial correlation) incelemesiyle anlaşılabilir. Çalışmada raporlanmayan sonuçlara göre $\mathrm{CFO}_{t}$ değişkeni kontrol altındayken $\Delta \mathrm{WC}$ ve $\mathrm{CFO}_{t+1}$ arasında pozitif ve anlamlı korelasyon katsayısı $(0,32)$ olduğu tespit edilmiştir.

\subsubsection{Tahakkuk Kalitesi Analiz Bulguları}

Firmalara ait tahakkuk kalitesi göstergelerinin tespit edildiği analiz bulguları Tablo 3'de raporlanmıştır. Tabloda raporlanan model her firma için ayrı ayrı kurulmuş ve elde edilen kalıntı değerlerin standart sapmaları hesaplanmıştır. Firmalara ait standart sapma değerleri de nihai tahakkuk kalitesi göstergesi olarak değerlendirilmiştir. Elde edilen yüksek standart sapma değerinin düşük tahakkuk kalitesi, düşük standart sapma değerinin ise yüksek tahakkuk kalitesi göstergesi olduğu kabul edilmiştir.

Tablo 3. Tahakkuk Kalitesi Model Bulguları

\begin{tabular}{|c|c|c|c|c|}
\hline Değişkenler & Katsayı & Std, Sapma & $\mathrm{t}$-İstatistik & Olasilik \\
\hline $\mathrm{C}$ & 0,06 & 0,00 & 16,61 & 0,00 \\
\hline $\mathrm{CFO}_{\mathrm{t}-1}$ & 0,25 & 0,02 & 14,01 & 0,00 \\
\hline $\mathrm{CFO}_{\mathrm{t}}$ & $-0,64$ & 0,02 & $-27,08$ & 0,00 \\
\hline $\mathrm{CFO}_{\mathrm{t}+1}$ & 0,20 & 0,02 & 8,24 & 0,00 \\
\hline Düzeltilmiş $\mathrm{R}^{2}$ & 0,53 & Durbin-Watson istatistiği & & 1,83 \\
\hline F-istatistik & 267,54 & Olas1lık(F-istatistik) & & 0,00 \\
\hline \multicolumn{5}{|c|}{$\begin{array}{l}\Delta W C=\beta_{0}+\beta_{1} C F O_{t-1}+\beta_{2} C F O_{t}+\beta_{a} C F O_{t+1}+\varepsilon_{t} \\
\Delta W C=(\triangle \text { Alacaklar }+\Delta \text { Stoklar }-\Delta \text { Borçlar }-\Delta \text { Ödenecek vergi }+\Delta \text { Diğer varlıklar }) \text { olarak hesaplanmıştır. } \\
\text { CFO = Firma nakit akış tablosunda yer alan faaliyetten sağlanan nakit akışını ifade etmektedir. } \\
\text { Tüm değişkenler otalama toplam varlıklarla deflate edilmiştir. }\end{array}$} \\
\hline
\end{tabular}

Tablo 3'de raporlanan sonuçlar inceleme döneminde tüm örneklem firmalarına aittir. Elde edilen bulgular incelendiğinde dönem çalışma sermayesi değişimlerinin bir önceki ve bir sonraki dönem nakit akışları ile pozitif yönlü ve anlamlı katsayılara sahip olduğu görülmektedir. Beklendiği gibi $\Delta \mathrm{WC}$ değişkeni ve $\mathrm{CFO}_{t}$ değişkeni arasında negatif yönlü ve anlamlı katsayı tespit edilmiştir. Modelin açıklama gücü 0,53 düzeyindedir.

\subsubsection{Kârın Süreğenliği Analizine Ait Bulgular}

İnceleme döneminde yer alana firmalara ait kârın süreğenliği katsayılarının hesaplandığı modele ait bulgular

Tablo 4'de raporlanmıştır. 
Tablo 4. Kârın Süreğenliği Model Bulguları

\begin{tabular}{lcccc}
\hline Tüm Örneklem Firmalarına Ait Bulgular & & & \\
\hline Değişkenler & Katsayı & Std, Sapma & t-İstatistik & Olasılık \\
C & 0,03 & 0,00 & 8,21 & 0,00 \\
Earnings $_{\mathrm{t}}$ & 0,57 & 0,03 & 19,65 & 0,00 \\
\hline${\text { Düzeltilmiş } \mathrm{R}^{2}}_{\text {F-istatistik }}$ & 0,33 & Durbin-Watson istatistiği & & 2,37 \\
\hline
\end{tabular}

Earning $_{t+1}=\beta_{0}+\beta_{1}{\text { Earning } s_{t}+\varepsilon_{t}}$

Earnings $=$ Firmaların gelir tablosunda yer alan dönem kârını ifade etmektedir.

Tablo 4'de raporlanan bulgular incelendiğinde örneklem firmalarının bir sonraki dönem kârı ve dönem kârı arasında pozitif ve anlamlı katsayıya $(0,57)$ sahip olduğu görülmektedir. Modelin genel olarak anlamlı olduğu F- istatistiğinden yola çıkılarak ifade edilebilir. Bu aşamadan sonra tahakkuk kalitesi ve kârın süreğenliğgi arasında ilişkiler incelenecektir.

\subsubsection{Tahakkuk Kalitesi ve Kârın Süreğenliği}

Çalışmada amaçlanan tahakkuk kalitesi ve kârın süreğenliği arasındaki ilişkinin incelenmesi için tahakkuk kalitesine göre gruplandırılan firmaların kâr süreğenliği değerlerine ihtiyaç duyulmaktadır. Söz konusu gruplandırma firmalara ait tahakkuk kalitesi modelinden elde edilen kalıntı değer standart sapmalarına göre yapılmıştır. Standart sapma değerleri hesaplanan firmalar, standart sapma değerleri küçükten büyüğe (yüksek tahakkuk kalitesinden düşük tahakkuk kalitesine) doğru sıralanmıştır. Elde edilen sıralama doğrultusunda firmalar dört gruba ayrılmıştır. İncelenen firma sayısına göre ilk üç grup 20 firmadan, dördüncü grup ise 19 firmadan oluşmaktadır. Bu kapsamda birinci grup, elde edilen standart sapma değerlerine göre en yüksek kalite göstergesine sahip firmalardan oluşmakta ve bu sıralama ikinci, üçüncü ve dördüncü gruba doğru azalarak devam etmektedir.

Söz konusu firma gruplarında yer alan firmalarla kârın süreğenliği tespit modeli her firma grubu için ayrı ayrı kurularak panel veri yöntemiyle incelenmiştir. Elde edilen bulgular Tablo 5'de sunulmuştur.

Tablo 5. Tahakkuk Kalitesine Göre Gruplandırılan Firmalara Ait Bulgular

\begin{tabular}{lcccc}
\hline \multicolumn{5}{l}{ Panel A: Tahakkuk Kalitesine Göre 1. Grup Firma Bulguları } \\
\hline Değişkenler & Katsayı & Std, Sapma & t-İstatistik & Olasılık \\
C & 0,00 & 0,00 & 2,33 & 0,02 \\
Earnings $_{\mathrm{t}}$ & 0,89 & 0,02 & 32,25 & 0,00 \\
\hline Düzeltilmiş $\mathrm{R}^{2}$ & 0,85 & Durbin-Watson istatistiği & 2,25 & \\
F-istatistik & 1040,39 & Olasılık(F-istatistik) & 0,00 & \\
\hline \multicolumn{5}{l}{ Panel B: Tahakkuk Kalitesine Göre 2. Grup Firma Bulguları } \\
\hline
\end{tabular}




\begin{tabular}{|c|c|c|c|c|}
\hline Değişkenler & Katsayı & Std, Sapma & $\mathrm{t}$-İstatistik & Olasılık \\
\hline $\mathrm{C}$ & 0,02 & 0,00 & 16,26 & 0,00 \\
\hline Earnings $_{\mathrm{t}}$ & 0,76 & 0,05 & 4,01 & 0,00 \\
\hline Düzeltilmiş $\mathrm{R}^{2}$ & 0,60 & Durbin-Watson istatistiği & 2,14 & \\
\hline F-istatistik & 264,66 & Olasıl1k(F-istatistik) & 0,00 & \\
\hline \multicolumn{5}{|c|}{ Panel C: Tahakkuk Kalitesine Göre 3. Grup Firma Bulguları } \\
\hline Değişkenler & Katsayı & Std, Sapma & t-İstatistik & Olasılik \\
\hline $\mathrm{C}$ & 0,04 & 0,00 & 4,65 & 0,00 \\
\hline Earnings $_{\mathrm{t}}$ & 0,57 & 0,05 & 10,77 & 0,00 \\
\hline Düzeltilmiş $\mathrm{R}^{2}$ & 0,39 & Durbin-Watson istatistiği & 1,84 & \\
\hline F-istatistik & 115,99 & Olasıl1k(F-istatistik) & 0,00 & \\
\hline \multicolumn{5}{|c|}{ Panel D: Tahakkuk Kalitesine Göre 4. Grup Firma Bulgularl } \\
\hline Değiş̧kenler & Katsayı & Std, Sapma & t-İstatistik & Olasılik \\
\hline $\mathrm{C}$ & 0,03 & 0,01 & 2,13 & 0,03 \\
\hline Earnings $_{\mathrm{t}}$ & 0,55 & 0,06 & 9,32 & 0,00 \\
\hline Düzeltilmiş $\mathrm{R}^{2}$ & 0,34 & Durbin-Watson istatistiği & 1,66 & \\
\hline F-istatistik & 94,31 & Olasıl1k(F-istatistik) & 0,00 & \\
\hline
\end{tabular}

Tablo 5'de raporlanan bulgular incelendiğinde modellerin genel olarak anlamlı olduğu ve her grupta yer alan firmalara ait kâr süreğenliği göstergesi olarak değerlendirilen Earnings $s_{t}$ değişkeninin pozitif ve anlamlı katsayılara sahip olduğu görülmektedir. Tahakkuk kalitesi göstergelerine göre oluşturulan gruplara ait bulgular daha yalın ve özet bir şekilde Tablo 6'da sunulmuştur.

Tablo 6. Gruplara Ayrılan Firma Bulgularının Karşılaştırılması

\begin{tabular}{lcccc}
\hline Gruplar & Std. Sapma & $\Delta \mathbf{W C}$ & Süreğenlik & Model $\mathbf{R}^{\mathbf{2}}$ \\
\hline 1. Grup & 0,011 & 0,046 & 0,897 & 0,853 \\
2. Grup & 0,021 & 0,071 & 0,761 & 0,595 \\
3. Grup & 0,036 & 0,086 & 0,577 & 0,392 \\
4. Grup & 0,057 & 0,107 & 0,555 & 0,335 \\
\hline
\end{tabular}

Tabloda yer alan std. sapma değerleri tahakkuk kalitesi göstergesi olarak değerlendirilmektedir ve her bir firma için aşağıdaki modelden elde edilen kalıntı değerlerin standart sapmaları alınarak hesaplanmıştır.

$\triangle W C=\beta_{0}+\beta_{1} C F O_{t-1}+\beta_{2} C F O_{t}+\beta_{2} C F O_{t+1}+\varepsilon_{t}$

$\Delta \mathrm{WC}=(\Delta$ Alacaklar $+\Delta$ Stoklar $-\Delta$ Borçlar $-\Delta$ Ödenecek vergi $+\Delta$ Diğer varlıklar $)$ olarak hesaplanmıştır.

$\mathrm{CFO}=$ Firma nakit akış tablosunda yer alan faaliyetten sağlanan nakit akışını ifade etmektedir.

Tüm değişkenler otalama toplam varlıklarla deflate edilmiştir.

Süreğenlik katsayısı tahakkuk kalitesine göre oluşturulan grup firmaları için aşă̆ıdaki model yardımıyla hesaplanmıştır.

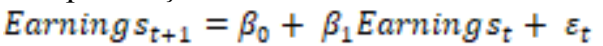

Earnings $=$ Firmaların gelir tablosunda yer alan dönem kârını ifade etmektedir.

Modelden her bir grup için elde edilen $\beta_{1}$ katsayısı süreğenlik katsayısı olarak dikkate alınmıştır.

Tablo 6'da raporlanan değerler incelendiğinde tahakkuk kalitesi (std. sapma) ve süreğenlik arasında pozitif yönlü bir trendin olduğu gözlemlenmektedir. Beklentiye uygun olarak tahakkuk kalitesi düştükçe (1. gruptan 4. gruba) kârın süreğenlik katsayısı ve model $\mathrm{R}^{2}$ 
değerinin de düştüğü (1. gruptan 4. gruba) görülmektedir. Tablo 6'da yer alan bulgular ayrıca tahakkuk kalitesi ve çalışma sermayesi değişimi arasındaki ilişki hakkında da bilgiler sunmaktadır. Elde edilen bulgulara göre, tahakkuk kalitesi arttıkça (grup 4 den grup 1 e) çalışma sermayesi değişimin boyutu küçülmekte ve içerdiği hata payının da beklenen bir bakış açısıyla azaldığı ifade edilebilir.

\section{SONUÇ}

$\mathrm{Bu}$ çalışmada firmaların tahakkuk kalitesi ile kâr süreğenliği arasındaki ilişki incelenmiştir. Çalışmada kullanılan tahakkuk terimi, çalışma sermayesindeki değişim olarak tanımlanmıştır. Çalışma sermayesindeki değişim, ticari alacaklardaki, stoklardaki, ticari borçlardaki, vergi yükümlülüklerindeki ve diğer dönen varlıklardaki değişim dikkate alınarak hesaplanmıştır. Söz konusu değişim, bir mali dönem içinde gerçekleşmesi beklenen olaylardan kaynaklanmaktadır. Bu nedenle tahakkukların bir dönem içinde (geçmiş, cari ve gelecek) nakit akışlarıyla eşleşeceği varsayılmıştır. Söz konusu eşleşmelerin gerçekleşmemesi tahakkuklarda bir düzeltmeyi gerektirecektir. Örneğin çalışma sermayesi tahakkuk grubunda yer alan ticari alacaklarda geçmiş dönemde meydana gelen artışın $\left(\Delta\right.$ Ticari Alacaklar $\left._{t-1}\right)$ bir sonraki dönemde nakit akışına $\left(\mathrm{CFO}_{t}\right)$ dönüşmesi beklenmektedir. Eğer $t$ - 1 döneminde gerçekleşen ticari alacak artışı bir sonraki dönemde ( $t$ döneminde ) nakit akışına dönüşmemiş ise, geçmiş dönem tahakkuk işlemlerinde tahmin hatası olduğu ifade edilebilir. Bir firmanın tahakkuk kalitesi de tahakkuk ve nakit akışı eşleşmesinin gerçekleşmesine bağlıdır.

Kâr, firmaların yayınladıkları finansal tablolarda yer alan firmanın dönem içindeki faaliyetlerinin finansal bir özeti olarak önemli bir yere sahiptir. Kâr aynı zamanda tahakkuk ve nakit akışı bileşenlerinden oluşmaktadır. Bu noktadan hareketle kâr ve tahakkuklar arasında güçlü bir ilişkinin olması yapısal bir sonuçtur. Bu çalışmada söz konusu ilişki BIST 100 indeksinde yer alan 79 firmaya ait 2005-2015 yıllarını kapsayan 706 firma-yıl gözlem seti kullanılarak incelenmiştir. Firmaların tahakkuk kaliteleri ve kâr süreğenlikleri literatürde mevcut olan modeller yardımıyla hesaplanmıştır.

Elde edilen sonuçlara göre firmaların tahakkuk kaliteleri ile kâr süreğenliği arasında pozitif yönlü bir ilişki tespit edilmiştir. Söz konusu bulgu kapsamında firmaların tahakkuk kaliteleri arttıkça kâr süreğenliği katsayılarının da arttığı ifade edilebilir.

Tahakkuk kalitelerine göre gruplandırılan firmaların kâr süreğenliği modellerinden elde edilen $R^{2}$ değerlerinin de tahakkuk kalitesiyle pozitif yönlü bir ilişkiye sahip olduğu belirlenmiştir. Yüksek tahakkuk kalitesine sahip firmaların yer aldığ gruba ait $R^{2}$ değerlerinin daha düşük tahakkuk kalitesine sahip firmaların yer aldığg grup $R^{2}$ değerlerinden daha yüksek olduğu tespit edilmiştir.

Aynı zamanda tahakkuk kalitesi düşen firmaların çalışma sermayesi değişimlerinin de arttığ1 gözlemlenmiştir. Söz konusu bulgu artan çalışma sermayesi değişimlerinin içerdiği tahakkuk büyüklügünün daha yüksek eşleşme hatalarına neden olduğu şeklinde değerlendirilmektedir.

Elde edilen bulgular literatürde yapılan çalışmalar kapsamında değerlendirildiğinde tutarlı sonuçlara ulaşıldığı, BIST 100 örnekleminde yer alan firmaların da daha önceki çalışmalarda incelenen firmalarla uyumlu bir yapıya sahip oldukları ifade edilebilir. Dechow 
ve Dichev (2002) tahakkuk kalitesine etkisi olan firma karakteristiklerini firmaların faaliyet döngü süresi, firma büyüklüğü, satış tutarı/nakit akışı/tahakkuk ve kâr oynaklığının yanında firmaların zarar raporlama sıklığı olarak ifade etmiştir.

Çalışma kapsamında model kalıntı değerlerinin standart sapmalarının hesaplanması için firmaya özgü modellerin kurulmuş olmasından dolayı her bir firmaya ait elde edilecek ilave geçmiş yıl gözlemlerinin elde edilecek sonuçları güçlendireceği beklenmektedir. $\mathrm{Bu}$ nedenle Türkiye örnekleminde çalışmanın ilerleyen dönemlerde daha fazla sayıda gözlem kullanılarak tekrarlanmasının faydalı olacağı değerlendirilmektedir. Diğer taraftan, çalışma kapsamında tek bir endeks incelenmiştir. Bir başka çalışma da sektörlere göre söz konusu ilişkilerin farklılaşıp farklılaşmadığını test edecek şekilde kurgulanabilir.

\section{KAYNAKLAR}

Board, F. A. S. (1978), Statement Of Financial Accounting Concepts, No. 1, Objective Of Financial Reporting By Business Enterprises.

Board, F. A. S. (1980), Statement Of Financial Accounting Concepts, No. 2, Qualitative Characteristics Of Accounting Information. Financ Acc Stand Board.

Chen, L. H. - Folsom, D. M.- Paek, W.- Sami, H. (2013), Accounting Conservatism, Earnings Persistence And Pricing Multiples On Earnings, Accounting Horizons, 28(2), pp. 233 260.

Dechow, P. - Ge, W. - Schrand, C. (2010), "Understanding Earnings Quality: A Review Of The Proxies, Their Determinants And Their Consequences", Journal Of Accounting And Economics, 50(2), pp. 344-401.

Dechow, P. M.- Dichev, I. D. (2002), "The Quality Of Accruals And Earnings: The Role Of Accrual Estimation Errors", The Accounting Review, 77(S-1),pp. 35-59.

Dechow, P. M.- Ge, W. (2006), "The Persistence Of Earnings And Cash Flows And The Role Of Special Items: Implications For The Accrual Anomaly", Review Of Accounting Studies, 11(2-3), pp.253-296.

Durak, M. G. (2010), Türkiye'de Uluslararası Finansal Raporlama Standartları'na Geçişin Tahakkukların Güvenilirliği Ve Kazançların Süreğenliği Üzerindeki Etkileri: İstanbul Menkul Kıymetler Borsası (İMKB) Uygulamalar1, Doctoral Dissertation, DEÜ Sosyal Bilimleri Enstitüsü.

Francis, J. - Lafond, R. - Olsson, P. - Schipper, K. (2005), "The Market Pricing Of Accruals Quality", Journal Of Accounting And Economics, 39(2), pp. 295-327.

Gray, P.- Koh, P. S. - Tong, Y. H. (2009), "Accruals Quality, Information Risk And Cost Of Capital: Evidence From Australia". Journal Of Business Finance \& Accounting, 36(12), pp. 51-72.

Gujarati, D. N. (2009), Basic Econometrics. Tata Mcgraw-Hill Education. 
Ittonen, K.- Vähämaa, E.- Vähämaa, S. (2013), "Female Auditors And Accruals Quality", Accounting Horizons, 27(2), 205-228.

Leal, L. T. Y.- Girao, L. F. D. A. P.- Lucena, W. G. L.- Martins, V. G. (2017), Persistence, Value Relevance, And Accruals Quality In Extreme Earnings And Cash Flow Situations", RAM. Revista De Administração Mackenzie, 18(3), pp. 203-231.

Li, F. (2008), "Annual Report Readability, Current Earnings And Earnings Persistence", Journal Of Accounting And Economics, 45(2), pp. 221-247.

Özkan, N.- Kayali, M. M. (2015), "Kazanç, Nakit Akımı Ve Tahakkuklarin Süreğenliği: Borsa İstanbul Üzerine Bir Araştirma", Dumlupinar University Journal Of Social Science/Dumlupinar Üniversitesi Sosyal Bilimler Dergisi, (43).

Palepu, K. G.- Bernard, V.- Healy, P. (2000), Business Analysis And Valuation (South. In: Western Publishing, Co Cincinnati, Ohio Google Scholar.

Richardson, S. A.- Sloan, R. G.- Soliman, M. T.- Tuna, I. (2002), "Information In Accruals About Earnings Persistence And Future Stock Returns", Ann Arbor, 1001, pp.4810941234.

Richardson, S. A.- Sloan, R. G.- Soliman, M. T.- Tuna, I. (2005), "Accrual Reliability, Earnings Persistence And Stock Prices", Journal Of Accounting And Economics, 39(3), pp.437-485.

Scholer, F. (2004), The Quality Of Accruals And Earnings And The Market Pricing Of Earnings Quality. Retrieved From

Sloan, A. (1996), "Create An Account Or Log In", Accounting Review, 71(3), pp.289-315.

Srinidhi, B.- Gul, F. A. (2007), "The Differential Effects Of Auditors' Non-Audit And Audit Fees On Accrual Quality", Contemporary Accounting Research, 24(2), pp. 595-629 